\title{
Performance and Techno-Economic Analysis of Inlet Fogging System Implementation in Heavy Duty Industrial Gas Turbines
}

\author{
Authors: R. Agbadede and B. Kainga \\ Department of Electrical Engineering, Nigeria Maritime University, Okerenkoko Warri, Delta State, Nigeria \\ Department of Mechanical Engineering, Nigeria Maritime University, Okerenkoko Warri, Delta State, Nigeria \\ E-mail: ${ }^{1}$ roupa.agbadede@nmu.edu.ng
}

Received 19 August 2020, Revised 14 February 2021, Accepted 31 March 2021

\begin{abstract}
This study investigates the performance and economic benefits of applying inlet fogging in a heavy duty industrial gas turbine. To achieve the aim of the study, a heavy duty industrial gas turbine engine was modelled using a gas turbine performance software, GasTurb. The modelled engine was derived from the Frame 9E class of gas turbines. Consequent upon completing the engine modelling, ambient temperature profile data obtained from a location in Niger Delta region of Nigeria were used as input into the engine model to simulate its effect on the engine performance. Inlet fogging was simulated on the industrial gas turbine by inputting a water-to-air ratio of $0.4 \%$, to cool and reduce the air inlet temperature by 10 degree Celsius. The simulation plots show that the gas turbine performance which dropped as a result of increased ambient temperature was enhanced by the application of inlet fogging. Economic analysis shows that approximately $\$ 2.4$ million profit was recorded in one year when inlet fogging system was employed.
\end{abstract}

\section{Keywords: Droplet Size; Ambient Temperature; Simulations; performance Analysis; Economic Analysis}

\section{Introduction}

The overall performance of gas turbine is adversely affected by high ambient temperatures. According to Sa and Zubaidy [1] gas turbines lose about $0.1 \%$ in thermal efficiency and $1.47 \mathrm{MW}$ of power for every $1 \mathrm{~K}$ rise in ambient temperature. As a result, different methods have been employed to reduce the air inlet temperature of the gas turbine in order to enhance the overall performance of the gas turbine, especially under high environmental temperatures. One of such techniques is the inlet fogging where clean water is injected to cool the gas turbine air inlet temperature. However, applying inlet fogging system to cool the air inlet temperature of the gas turbine involves expenses such as the procurement of the fogging system, cost of extra fuel consumed, cost of water consumed, cost of power consumed by the fogging system etc. Hence, prior to installing an air inlet fogging system for any gas turbine plant, there is the need to carefully examine system parameters and investment criteria.

A gas turbine air inlet cooling system which uses solar absorption chiller was presented in (Rahman and Mokheimer [2]. Chaker and Meher-Homji [3] conducted an experimental and theoretical investigation on impaction pin fog nozzle behaviour. The study demonstrated that the measured droplet size reduced with increased injection velocity. Also, the study reveals that it takes longer response time for larger droplet to adjust the airflow velocity than a smaller droplet. A study relating to inlet fogging considerations in gas turbine ship drive application was presented [4]. A numerical investigation of different inlet cooling technologies applied in integrated gasification combined cycle power plants was presented in Pascale [5]. The study revealed that evaporative cooling proved to be a reliable option for power augmentation in IGCC. Similarly, Dawoud et al. [6] conducted an evaluation of the impact of different cooling technologies on power boosting in gas turbines. The cooling techniques were compared based on the electric energy generation enhancement. It was reported that when fog cooling technique was applied on the gas turbine, the electrical energy generated was more compared to evaporative method.

Utamuru et al. [7] presented a cost estimate method to compare inlet cooling systems for power enhancement combustion turbine. System design parameters were arranged in a dimensionless form using a conversion index. Chalker et al.[8] presented a tabulation, which determines the feasibility of evaporative cooling to specific locations. The evaporation dynamics of fog droplets injected at the inlet ducts were investigated in Chaker et al.[3]. Roumeliotis and Mathiodakis [9] used wet compression to analyze the effects of overspray on the compressor operation and performance. The effect of overspray on the compressor operation was carried out using a model derived from Tonando engine. The authors stated that wet compression caused a significant stage re-matching, moving the speed lines toward higher mass flow rate. In addition, it was stated that over spraying resulted in increased gain in efficiency and power output due to reduced compressor specific work and increased mass flow rate. Meher-homji and Mee [10] presented practical issues relating to high pressure inlet fogging system implementation. The study reported the use of high pressure inlet systems which comprised specialized nozzles to create fine droplet at the inlet duct of gas turbine. According to the authors these fine droplets are generated by specialized nozzles connected through a hose to high pressure pump 
operated at 1000-2000psi. Unlike the evaporative system, the high pressure fogging system requires only slight modifications of the inlet system. When installing fogging system for power augmentation, the quality and quantity of water required, need to be given due consideration. According to Meher-homji and Mee [10] the quantity of water required for a fogging system depends on a number of factors such as the ambient temperature, degree of cooling required and engine mass flow rate. Wang and Braquet [11] stated that inlet fogging systems are simple and less expensive to install when compared to other power augmentation options. Also, the issue of pressure drop associated with other systems is almost negligible with inlet fogging systems. In locations where fresh water is readily available, applying inlet fogging will definitely offer the best and quickest return on investment. The study of Gajjar et al. [12] described the design, installation, commissioning and operation of large scale inlet fogging system for a combined cycle power plant. In addition, technical details and practical issues relating inlet fogging system installation were also provided.

Most inlet fogging simulation studies available in the open domain - Chaker and Meher-Homji [13], Wang and Barquet [11] have all used relative humidity as input to simulate the effect inlet fogging on the gas turbine performance, instead of water-to-air ratio. The best method to account for the quantity of water required for providing inlet air cooling is the water-to-air ratio. This is because the fluid flow rate is assessed on mass-based water-to-air ratio which is a non-dimensional parameter for the liquid content [14]. In this study, the inlet fogging simulations were conducted using the water-to-air ratio, to account for the quantity of water required to achieve a given degree of cooling. Also, an economic analysis was carried out to ascertain the economic viability of the application of inlet fogging system.

\section{Materials and Methods}

\subsection{Effect of Ambient Temperature Simulations}

To simulate the influence of ambient temperature on the gas turbine performance, temperature profile obtained from a location in the Niger Delta region of Nigeria was employed (see Figure 1). As can be seen from the figure, ambient temperatures vary from $21^{\circ} \mathrm{C}$ to $33^{\circ} \mathrm{C}$ between low and high temperatures annually.

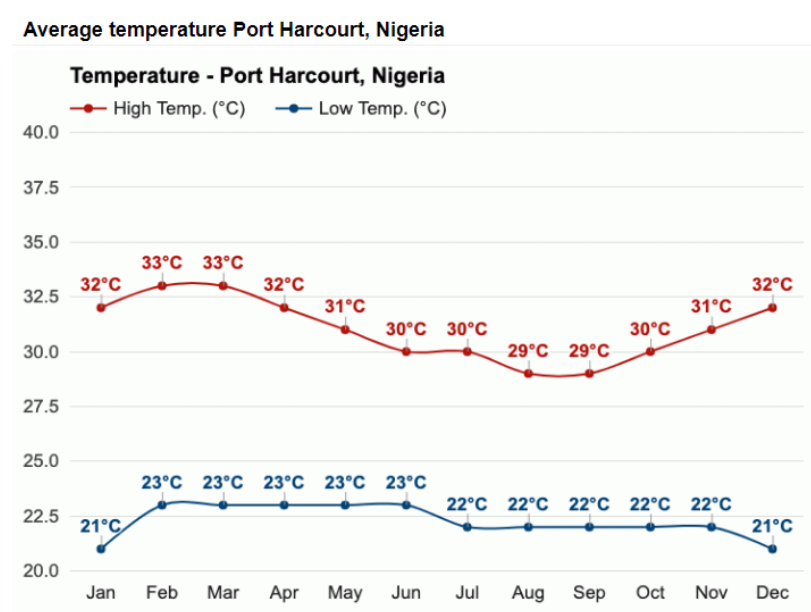

Figure 1: Ambient temperature profile data [15]
To simulate the effect of ambient temperature on gas turbine performance, a gas turbine performance simulations software, Gasturb was employed. GasTurb simulation Software employed in this study utilizes predefined engine configurations, thus allowing for an immediate start of calculations. GasTurb is designed for easy evaluation of the thermodynamic cycle both for design and off-design performances of the gas turbine. In addition, the software utilizes basic gas dynamic principles where thermodynamic equations such as gas, conservation of mass, conservation of momentum etc. were incorporated, to carry out the evaluation of the gas turbine performance. Some of the basic thermodynamic equations in embedded in the software for the calculation of the engine performance are presented from Equations (1) - (8):

Compressor work:

$$
C_{w}=w_{\text {air }} C_{p \text { air }}\left(T_{3}-T_{2}\right)
$$

Compressor isentropic efficiency,

$$
\eta_{i s C}=\frac{P R^{\frac{\gamma-1}{\gamma}}-1}{\frac{T_{3}}{T_{2}}-1}
$$

Combustor Efficiency:

$$
\eta_{c o m b}=\frac{\left(T_{4}-T_{3}\right) C_{p}}{F A R * L H V}
$$

Turbine work:

$$
\mathrm{T}_{\mathrm{w}}=W_{g a s} C_{p g a s}\left(T_{4}-T_{5}\right)
$$

Turbine efficiency:

$$
\eta_{i s T}=\frac{1-\frac{T_{5}}{T_{4}}}{1-\left(\frac{P_{5}}{P_{4}}\right)^{\frac{\gamma-1}{\gamma}}}
$$

Corrected Mass Flow;

$W_{\text {exit Corr }}=W_{\text {inlet corr }} * \frac{\sqrt{T_{\text {exit } / T_{\text {inlet }}}}}{P_{\text {exit }} / P_{\text {inlet }}}$

Thermal Efficiency, $\eta_{t h}$

$\eta_{t h}=\frac{U W}{H I}$

Based on the capabilities and features of the simulation software, it was employed to simulate the effects of ambient temperature and inlet fogging on gas turbine engine performance. Engine data obtained from open domain were used to model the single shaft heavy duty industrial gas turbine in the GasTurb simulation software. The modelled engine was derived from the Frame 9E class of gas turbines. Figure 2 shows the industrial gas turbine engine configuration model selected from software interface, while Table 1 presents the design point performance specifications. Consequent upon completing the engine modelling, ambient temperature data obtained from a location in Niger Delta region of Nigeria were used as input 
into the engine model to simulate its effect on the engine performance. When simulating the ambient temperature effect on GasTurb, the ambient temperatures profile of low and high values obtained were taken into considerations. As a result, the ambient temperatures were varied from $15^{\circ} \mathrm{C}$ to $35^{\circ} \mathrm{C}$ in steps of $5^{\circ} \mathrm{C}$, taking into consideration the lowest and highest ambient temperatures attainable in the Niger Delta Region of Nigeria.

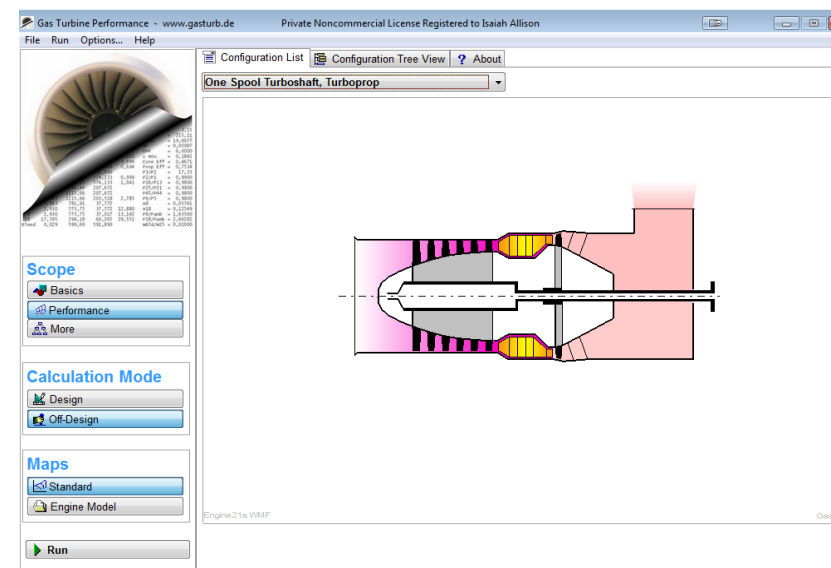

Figure 2: Industrial gas turbine engine configuration

Table 1: Engine design specifications (Courtesy of General Electric)

\begin{tabular}{ll}
\hline Design parameters & Units \\
\hline Power output & $120.6 \mathrm{MW}$ \\
Thermal efficiency & 34 \\
PR & 12.3 \\
Exhaust temperature & $850 \mathrm{~K}$ \\
Exhaust flow & $358 \mathrm{~kg} / \mathrm{s}$
\end{tabular}

\subsection{Inlet Fogging Simulations}

To ascertain the quantity of water required to achieve a given degree of cooling for the engine investigated, the methodology employed by Meher-homji and Mee [10] was used. This was done so as to ascertain the quantity of water required to provide inlet fogging for the gas turbine under investigation at varying ambient temperature.

According to Meher-homji and Mee [10] the quantity of water required to cool the air inlet temperature using fogging system depends on a number of factors such as the ambient temperature, degree of cooling required and engine mass flow rate. Also, the authors stated that there are other practical factors which need to be considered when estimating the quantity of water required. In addition, the authors presented a table which estimates the quantity of water required for defined degrees of cooling for different engine mass flow rates (see Table 1). In this study, to calculate the quantity water required for the engine under investigation, the values specified by Meher-homji and Mee [10] was adopted. In addition, based on the quantity of water required for a specified range of engine mass flow rates, the water-to-air ratio was calculated for the mass flow rate similar to the engine under investigation. A water-to-air ratio of $0.4 \%$ was obtained from the calculation and this value was used to derive the quantity water required for effective power augmentation, for the engine investigated.
GasTurb software was also employed to simulate the inlet fogging for the engine under investigation. Water-toair ratio of $0.4 \%$ derived from the calculations was used to simulate inlet fogging. Figure 3 shows the GasTurb interface where water-to-air of $0.4 \%$ was used as input into the software, to simulate inlet fogging. All gas turbine performance simulations were carried out using the default natural gas fuel provided in the software. It then followed by inputting the water-to-air ratio of $0.4 \%$ obtained from the calculation to simulate the inlet fogging investigation so as to enhance the performance of the gas turbine.

Table 2: Estimated water requirement for different engine mass flow rates to provide a given degree of cooling [10]

\begin{tabular}{llll}
\hline $\begin{array}{l}\text { Engine } \\
\text { mass flow } \\
\text { rate(kg/s) }\end{array}$ & $\begin{array}{l}\text { Litre/hr for } \\
\mathbf{1}^{\mathbf{0}} \mathrm{C} \text { cooling }\end{array}$ & $\begin{array}{l}\text { Litre/hr for } \\
\mathbf{5}^{\mathbf{0}} \mathbf{C} \text { cooling }\end{array}$ & $\begin{array}{l}\text { Litre/hr for } \\
\mathbf{1 0}^{\mathbf{0}} \mathbf{C} \\
\text { cooling }\end{array}$ \\
\hline $\mathbf{2 0 2}$ & 299 & 1495 & 2290 \\
$\mathbf{2 2 7}$ & 336 & 1682 & 3364 \\
$\mathbf{3 7 0}$ & 458 & 2738 & 5476 \\
$\mathbf{4 2 0}$ & 621 & 3107 & 6213 \\
$\mathbf{4 5 9}$ & 679 & 3397 & 6793 \\
\hline
\end{tabular}

\begin{tabular}{|c|c|c|c|c|c|}
\hline 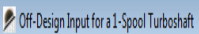 & \multicolumn{3}{|c|}{ Private Nonconmercial license Regigtered to bsaith Alison } & $\exists$ & 므 可 \\
\hline \multicolumn{6}{|c|}{ 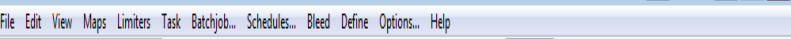 } \\
\hline Gead & 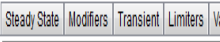 & Geometrin V V & teristeam Fogging leeration & Ful: & \\
\hline SFlotictor & 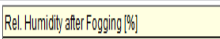 & & 0 & Natual Gas & - \\
\hline FFlle fisioy & 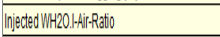 & & 0.004 & & \\
\hline 日 Sare as & Elaponation dWarldidemp & $11 / k$ & 00005 & & \\
\hline Apint & PowerMH-20. @ @ Nom.Speed & WN( $(0, k)$ & 0 & & \\
\hline & Woter Tennperitule & k & 288.15 & & \\
\hline
\end{tabular}

Figure 3: Inlet fogging simulation interface.

\section{Results and Discussion}

\subsection{Ambient Temperature Performance analysis}

Figures 4, 5 and 6 show the plots of ambient temperature variations against engine performance parameters of power output, thermal efficiency and heat rate respectively. Figure 4 shows that power output dropped from $120,630 \mathrm{~kW}$ to $109,550 \mathrm{~kW}$ when ambient temperature was increased from $288.15 \mathrm{~K}\left(15^{\circ} \mathrm{C}\right)$ to $308.15 \mathrm{~K}\left(35^{\circ} \mathrm{C}\right)$. This reduction in power out with increased ambient temperature can be attributed to reduced mass flow rate caused by reduction air flow density. Increased ambient temperature causes a reduction air flow density, which results in a drop in mass flow rate. Similarly, when ambient temperature was increased from $288.15 \mathrm{~K}\left(15^{\circ} \mathrm{C}\right)$ to $308.15 \mathrm{~K}\left(35^{\circ} \mathrm{C}\right)$, the thermal efficiency dropped from 0.337 to 0.327 as shown in Figure 5. The reduction in thermal with increased ambient temperature is caused by the reduction in pressure ratio, which is also as a result of mass flow reduction. Contrary to the plots of thermal efficiency, plot in Figure 6 shows increased heat rate with ambient temperature. This is expected because heat rate is the inverse of thermal efficiency. 


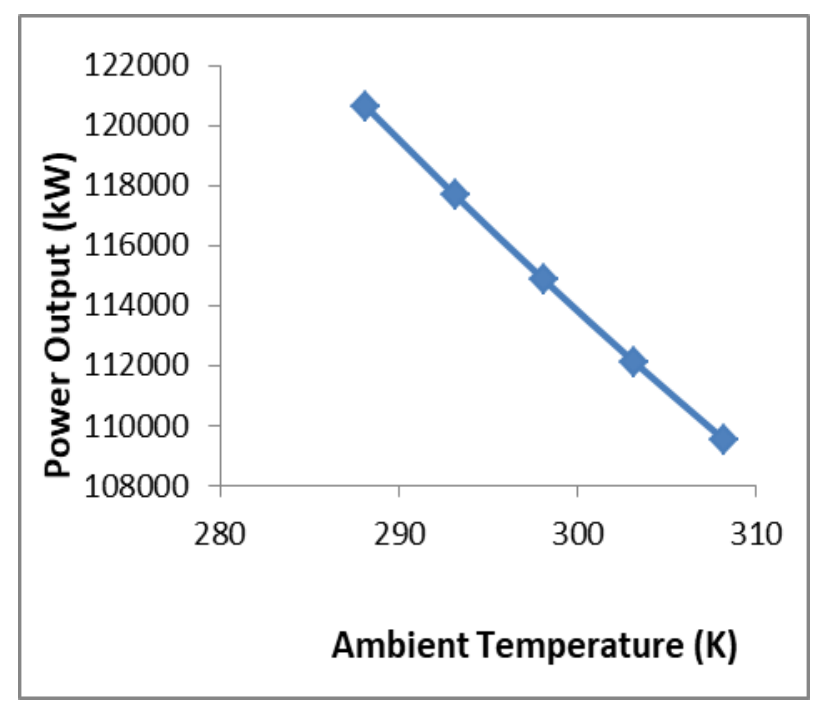

Figure 4: Power output against ambient temperature

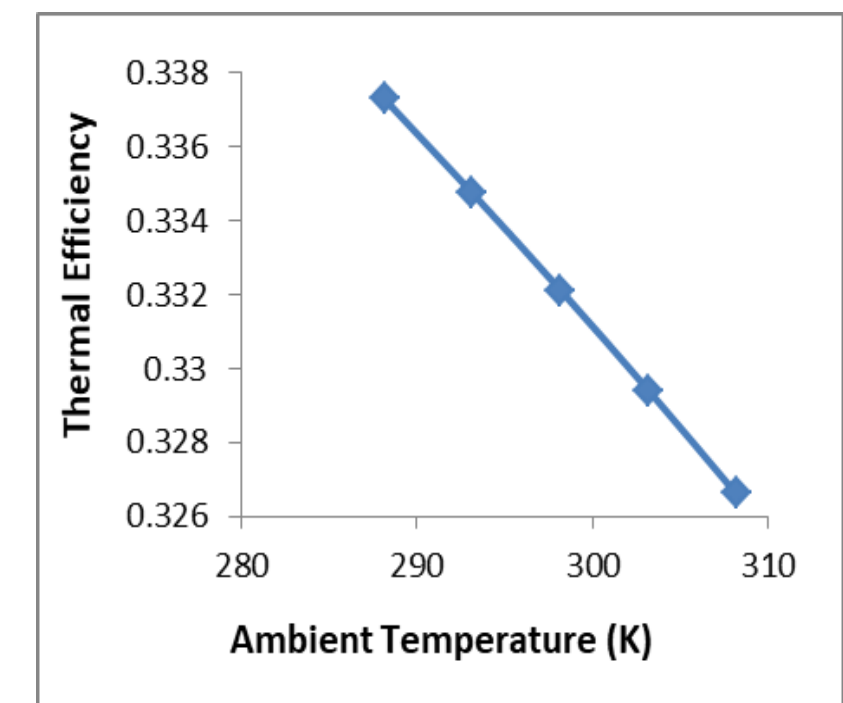

Figure 5: Thermal efficiency against ambient temperature

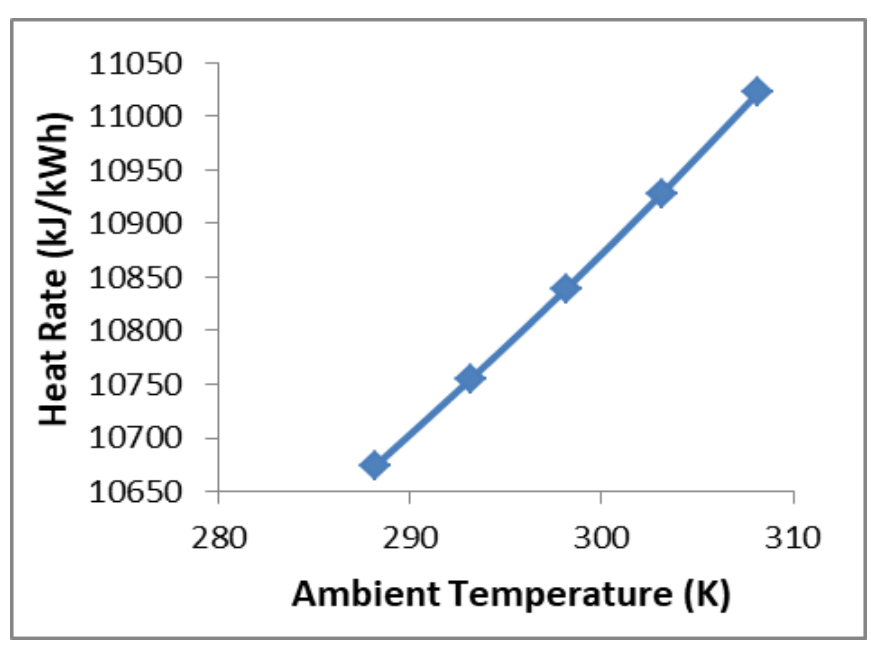

Figure 6: Heat rate against ambient temperature
Figure 7 shows the plot of power output against different conditions. When ambient temperature was increased from design condition of 288.15 to $298.15 \mathrm{~K}$, the power output dropped from $120631 \mathrm{~kW}$ to $114839 \mathrm{~kW}$, which is approximately $4.8 \%$ reduction in power output. However, when inlet fogging (water-to-air ratio of $0.4 \%$ ) was applied to the increased ambient temperature condition of $298.15 \mathrm{~K}$, the power output increased from 114839 to $119889 \mathrm{~kW}$, which is $4.2 \%$ increase in power output. As can be seen in Figure 8, the plots of thermal efficiency are similar to that of power output when inlet fogging (waterto-air ratio of $0.4 \%$ ) was applied to provide cooling for a situation where ambient temperature increased by $10^{\circ} \mathrm{C}$ from its design condition. Although the levels of percentage changes in thermal efficiency obtained are quite low as against power output. For heat rate plots shown in Figure 9, when ambient temperature was increased from design condition of 288.15 to $298.15 \mathrm{~K}$, the heat rate increased from $10673 \mathrm{~kJ} / \mathrm{kWh}$ to $10839 \mathrm{~kJ} / \mathrm{kWh}$, which is about 1.55 $\%$ increase. However, when inlet fogging (water-to-air of $0.4 \%$ ) was applied to cool the increased ambient air inlet temperature, the heat rate dropped from $10839 \mathrm{~kJ} / \mathrm{kWh}$ to $10668 \mathrm{~kJ} / \mathrm{kWh}$. The findings from the investigation are in agreement with the study of Meher-Homji and Mee [10], especially the percentage of performance enhancement achieved with inlet fogging.

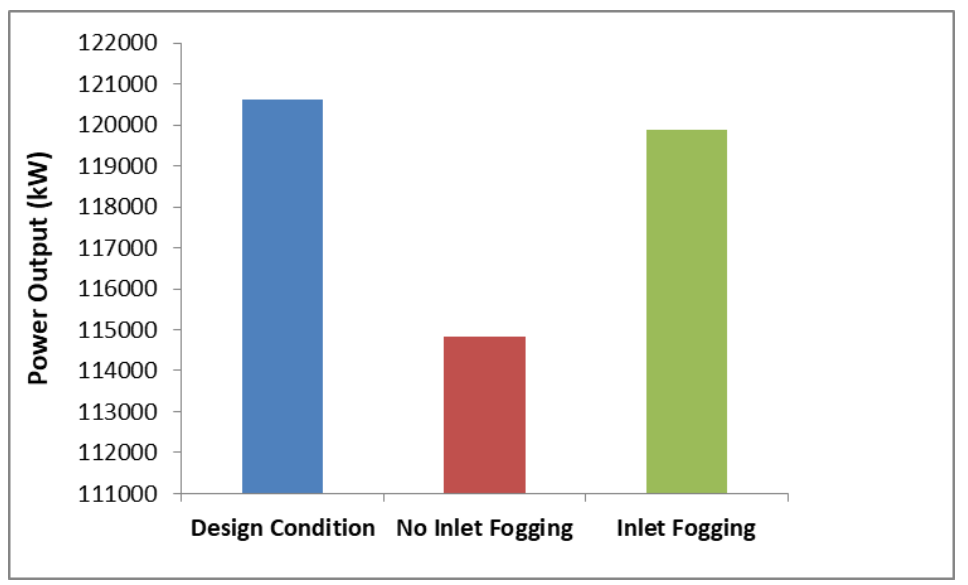

Figure 7: Power Output against different operating conditions

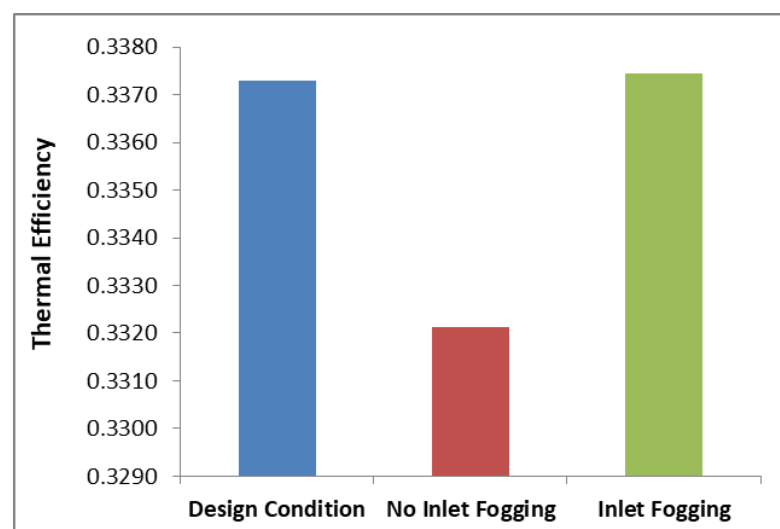

Figure 8: Thermal efficiency against different operating conditions

\subsection{Inlet Fogging Simulation Analysis}




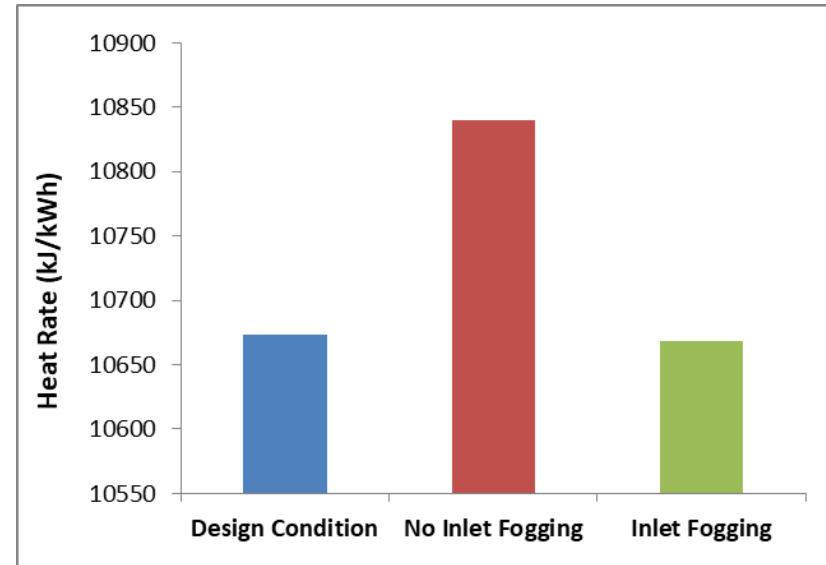

Figure 9: Heat rate against different operating conditions

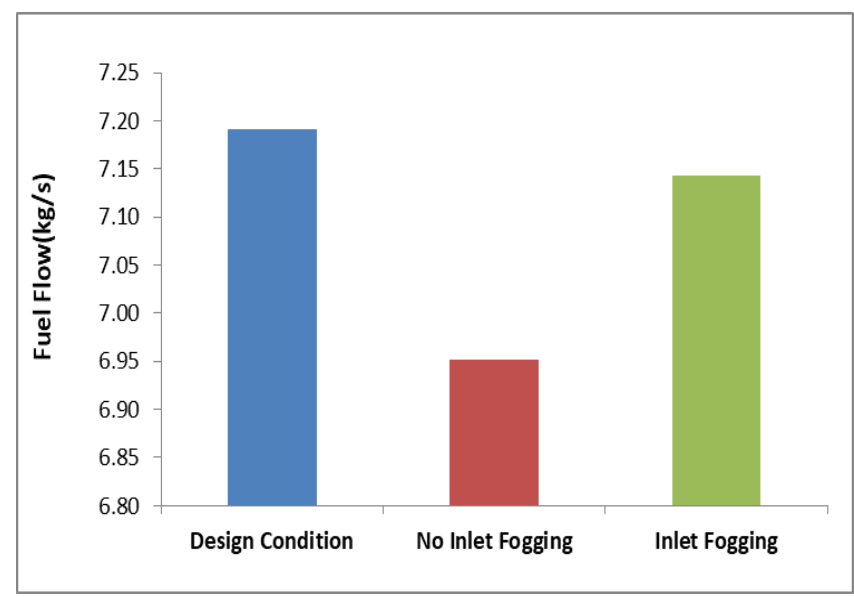

Figure 10: Fuel Flow against different operating conditions

\subsection{Techno-economic Analysis}

Since implementing inlet fogging in gas turbines involves expenses such as acquiring of fogging system, demineralized water, manpower etc. It is imperative to conduct economic analysis to ascertain if it is economically viable. To conduct the techno-economic analysis for the inlet fogging system, the different parameters, namely installed cost of inlet fogging system, costs of water required, extra fuel consumed, electric power consumed by the fogging system, operation and maintenance and the extra electric power gained by means of inlet fogging were considered.

\subsubsection{Installed Cost of Fogging system}

Capital cost of fogging system was estimated by adopting the suggestions provided in Wang and Braquet [11]. The authors stated that the cost of inlet fogging system installed in larger and utility gas turbines are in the range of $\$ 30-\$ 50 / \mathrm{kW}$ of the added power. Similarly, Celis et al.[16] in their study adopted $35 / \mathrm{kW}$ of power added as the cost of fogging system. From the foregoing, the value of $\$ 35 / \mathrm{kW}$ added power was adopted to calculate the installed cost of the inlet fogging system for the industrial gas turbine under investigation.

From the fogging simulations, when fogging was implemented for the industrial gas turbine operated under increased ambient temperature of $298.15 \mathrm{~K}$, the engine gained $5050 \mathrm{~kW}$ power output.
Therefore, installed capital cost of fogging system $=$ $\$ 35 / \mathrm{kW} \times 5,050 \mathrm{~kW}=\$ 176,750$

\subsubsection{Annual Fuel Cost arising from Power} Augmentation

The extra fuel consumed was calculated from the difference in fuel flow under fogging and no fogging conditions.

Extra fuel consumed per hour $=687.97 \mathrm{~kg} / \mathrm{hr}$

A capacity factor of $91.3 \%$ was assumed - implying the engine operated 8000 hour/year

Therefore, fuel consumed annually $=687.97 \mathrm{~kg} / \mathrm{hr} \times$ $8,000 \mathrm{hr}=5,503,200 \mathrm{~kg}$

Fuel cost $=\$ 0.1275 / \mathrm{kg}[17]$

Annual cost of fuel consumed $=\$ 0.1275 / \mathrm{kg} \mathrm{x}$ $5,503,200 \mathrm{~kg}=\$ 701,658$

\subsubsection{Cost of Electric Energy Consumed by Fogging} System

Chaker and Meher-Homji [13] stated that the maximum parasitic power of fogging systems used for large gas turbines is in the range of $50-80 \mathrm{~kW}$ when the maximum wet bulb depression is to be derived. Therefore, in this study, $60 \mathrm{~kW}$ was adopted as the power consumed by the fogging system.

Electricity consumed annually $=60 \mathrm{~kW} \times 8000 \mathrm{~h}$ $=480,000 \mathrm{kWh}$

According to Allison [18], the prices of electricity typically vary depending on location, as well as customer type. In Abuja, Nigeria, electricity price was raised from N13.25 (\$0.08) to N14.70 (\$0.09) per kilowatt/hour (KWh).

Therefore, cost of electricity consumed $=480,000 \mathrm{kWh}$ $\mathrm{x} \$ 0.09 / \mathrm{kWh}=\$ 43,200$

\subsubsection{Operation and Maintenance Cost of Fogging System}

Operation and maintenance cost of $3 \%$ of total capital cost was adopted from Allison [18]

Therefore, $0.03 \times \$ 176,750=\$ 5,302.5$

Cost water consumed

Water flow rate for one hour $=5040$ litres $/$ hour

Annual water consumed cost $=5040 \times 8000=40,320,000$ litres $=40,320 \mathrm{~m} 3$

Cost of water $=\$ 1.5 / \mathrm{m} 3[19]$

Therefore, annual cost of water consumed $=\$ 1.5 / \mathrm{m} 3 \mathrm{x}$ $40,320 \mathrm{~m} 3=\$ 60,480$

3.3.5 Extra Power Gained by means of Inlet Fogging

Power gained by means of inlet fogging $=5050 \mathrm{~kW}$

Capacity factor of the gas turbine plant was assumed to be $91.3 \%$ (8000hours)

Therefore, Electricity generated annually $=5050 \times 8000$ $=40,400,000 \mathrm{kWh}$

Extra power gained annually $=5050 \times 8000$ $=40,400,000 \mathrm{kWh}$

Cost of electricity is $\$ 0.09 / \mathrm{kWh}$ [19]

Therefore, cost of electricity gained annually = $40,400,000 \mathrm{kWh} \times \$ 0.09 / \mathrm{kWh}=\$ 3,363,000$ 
Table 4: Economic analysis

\begin{tabular}{ll}
\hline Parameters & Cost \\
\hline Cost of inlet Fogging system & 176,750 \\
Cost of Fuel consumed & $\$ 701,658$ \\
Cost of Water Consumed & $\$ 60,480$ \\
Cost of Electricity consumed & $\$ 43,200$ \\
by fogging system & \\
Operation and Maintenance & $\$, 5302$ \\
Cost & \\
Total Cost & $\mathbf{\$ 9 8 7 , 3 9 0}$ \\
Cost of Extra Electricity & $\$ 3,363,000$ \\
Generated & \\
Total Profit & $\mathbf{\$ 2 , 3 7 5 , 6 1 0}$ \\
\hline
\end{tabular}

\subsection{Conclusion}

The performance and economic analysis of the application of inlet fogging system in a heavy gas turbine engine is presented in the work. GasTurb performance simulation software was employed to model and simulate the performance of the gas turbine under fogging and no fogging conditions. Also, Gasturb simulation software was employed to simulate the effect of varying ambient temperatures. Based on practical field data on inlet fogging applications in gas turbines, a water-to-air ratio of $0.4 \%$ was obtained for the engine under investigation. Consequently, the inlet fogging simulations were done using water-to-air of $0.4 \%$, to account for the quantity water injected.

The ambient temperature simulations show that power output and thermal efficiency reduced with increased ambient temperature. Also, when inlet fogging was applied under increased ambient temperature condition, the power output and thermal efficiency increased. In addition, when techno-economic analysis was conducted on the application inlet fogging system under increased ambient temperature, a profit of approximately $\$ 2.4$ million was recorded.

\section{Acknowledgement:}

The authors are exceedingly grateful to Nigeria Maritime University for the technical support.

\section{References:}

[1] D. A. Sa and A. S. Zubaidy "Gas Turbine Performance at Varying Ambient Temperatures", Applied Thermal Engineering, 31 pp2735-2739, 2011.

[2] A. A. A. Rahman and A. M. E. Mokheimer "Boosting Gas Turbine Combine Cycles in Hot Regions using Air Inlet Cooling Including Solar Energy", Energy Procedia, 45 pp. 1509-1515, 2017.

[3] M. Chaker, C. B. Meher-Homji and T. Mee III “ Inlet Fogging of Gas Turbine Engines - Experimental and analytical investigation on Impaction Pin Fog Nozzle Behaviour", Proceeding of ASME Turbo Expo 2003 Power for Land, Sea and air, June 16-19, 2003, Atlanta, Gorgia, USA.

[4] Z. Domachowski and M. Dzida, "Inlet Air Fogging of Maritime Gas Turbine Power Output Compensation", Polish Maritime Research, 22 pp. 53-58, 2015.

[5] D. A. Pascale, F. Melino and M. Morini "Analysis of
Air Inlet Cooling for IGCC Power Augmentation", Energy Procedia, 45 pp. 1265-1274, 2014.

[6] B. Dawoud, H. Y. Zurigat and J. Bortmany “" Thermodynamic Assessment Of Power requirement and Impact of different Gas Turbine Inlet Air Cooling Techniques at two Different locations in Oman", Applied Thermal Engineering, 25 pp. 1579-1598, 2004.

[7] M. Utamura, Y. Nishimura, A. Ishikawa and N. Ando " Economics of Gas Turbine Inlet Air Cooling System for Power Enhancement”, ASME June 10-13, 1996, Birmigham, UK.96-GT-516, 1996.

[8] M. Chaker, C. B. Meher-Homji, T. Mee III and A. Nicholson " Inlet Fogging of Gas Turbine Engines Detailed Climatic analysis of Gas Turbine Evaporative Cooling Potential in the USA", Proceeding of ASME Turbo Expo 2001, June 4-17, 2001, New Orleans, USA.

[9] I. Roumeliotis and K. Mathioudakis "Evaluation of Water Injection Effect on Compressor and Engine Performance and operability", Applied Energy, 87 pp. 1207-1216, 2010.

[10] C. B. Meher-Homji and T. Mee III "Inlet Fogging of Gas Turbine Engines - Part B: Practical Considerations, Control and O\&M Aspects", Proceeding of ASME Turbo Expo 2001, Paper No. 2000-GT-308, May 8-11, 2000, Munich, Germany.

[11] T. Wang and L. Braquet “ Assessment of Inlet Cooling to Enhance Power output of a Fleet of Gas turbines", Proceeding of Industrial Energy Technology Conference IETC 30th, May 6-9, 2008, New Orleans, USA.

[12] H. Gajjar, M. Chaker, A. Dighe and C. B. MeherHomji " Inlet Fogging for a 655MW Combined Cycle Power plant - Design, Implementation and Operating Experience", Proceeding of ASME Turbo Expo 2003, June 16-19, 2003, Atlanta, Gorgia, USA.

[13] M. Chaker and C. B. Meher-Homji, "Inlet Fogging of Gas Turbine Engines: Climatic analysis of Gas Turbine Evaporative Cooling Potential of International Locations", Proceeding of ASME Turbo Expo 2001, June 3-6, 2002, Amsterdam, The Netherlands.

[14] E. Syverud "Axial Compressor Performance Deterioration and Recovery through Online Washing, (PhD thesis), Norwegian University of Science and Technology, 2007.

[15] (https://www.weather-nga.com/en/nigeria/portharcourt-climate\#climate text_2)(Accessed:16 Aug. 2020).

[16] C. Celis, D. P. V. Avellar and B. S. Ferreira "Power Augmentation Technologies for Gas turbines: A review and Study of Their Influence on the Performance of Simple Cycle Power Plant", 19thInternational congress of Mechanical Engineering, November 5-9, 2007, Brasila.

[17] S. S. Baakem, J. Orfi and H. Al-ansary " Performance Improvements of gas Turbine power plants utilizing turbine inlet air cooling, (TIAC) technogies in Riyadh, Saudi Arabia", Applied Thermal Engineering, vol.138 pp.417-432, 2018. 
[18] I. Allison "Techno-economic Evaluation of Associated Gas Usage for Gas Turbine Power Generation in the Presence of Degradation and Resource Decline" (unpublished PhD thesis), Cranfield university, Cranfield, 2014.
[19] O. Agwu, A. Oboh and S. Oliver"Techno-economic Evaluation of Mechanical Chiller for power Recovery in a Gas turbine Unit in Nigeria”, European Journal of engineering and Technology vol. 7 no. 4 pp. 6-17, 2019. 